\title{
Radioactive iodine treatment of papillary thyroid carcinoma in Japan
}

\author{
Takahiro Okamoto $^{1}$, Yoko Omi ${ }^{1}$, Yusaku Yoshida ${ }^{1}$, Kiyomi Horiuchi ${ }^{1}$, Koichiro Abe ${ }^{2}$ \\ ${ }^{1}$ Department of Breast and Endocrine Surgery, Tokyo Women's Medical University, Shinjuku-ku, Tokyo, Japan; ${ }^{2}$ Department of Radiology, Tokyo \\ Medical University, Shinjuku-ku, Tokyo, Japan \\ Contributions: (I) Conception and design: All authors; (II) Administrative support: None; (III) Provision of study materials or patients: None; (IV) \\ Collection and assembly of data: None; (V) Data analysis and interpretation: All authors; (VI) Manuscript writing: All authors; (VII) Final approval of \\ manuscript: All authors. \\ Correspondence to: Takahiro Okamoto, MD, MSc. Department of Breast and Endocrine Surgery, Tokyo Women's Medical University, 8-1 Kawada- \\ cho, Shinjuku-ku, Tokyo 162-8666, Japan. Email: okamoto.takahiro@twmu.ac.jp.
}

\begin{abstract}
We have a unique history of using radioactive iodine (RAI) therapy and surgical treatment for thyroid cancer in Japan. Less than total thyroidectomy without RAI therapy was the most common management of papillary thyroid carcinoma (PTC) in the past. Limited availability of dedicated facilities for the RAI administration due to the strict regulations and insufficient coverage of the expenses were the major reasons that impacted on the management decisions. Following the publication of the Japanese clinical practice guidelines for thyroid tumors in 2010, the risk-adapted approach has become a standard where the high-risk and selected intermediate-risk PTC patients undergo total thyroidectomy followed by RAI therapy and thyrotropin suppression therapy. We are on the shoulders of pioneers who made every effort to bring the interventions closer to an ideal environment for patients. Armed with the revised clinical practice guidelines 2018 and devised inpatient/outpatient RAI therapy, Japanese physicians are ready to proceed to more rational management that would improve patients' outcomes. Directions for the future include further advancement of relevant clinical research to fill the gaps between current evidence and recommendations in the guidelines, and obtaining approval for high-dose RAI therapy on an outpatient basis to improve its effectiveness in both adjuvant and treatment settings.
\end{abstract}

Keywords: Radioactive iodine (RAI); outpatient-based ablation; papillary thyroid carcinoma (PTC); risk classification; clinical practice guidelines

Submitted Mar 21, 2020. Accepted for publication May 17, 2020.

doi: 10.21037/gs-20-378

View this article at: http://dx.doi.org/10.21037/gs-20-378

\section{Introduction}

Radioactive iodine (RAI) therapy is one of the mainstays for managing patients with differentiated thyroid carcinoma (DTC) and has a definitive role in selected cases with distant metastases (1). However, the effectiveness of ablative or adjuvant RAI therapy for preventing oncologic events in surgically curable diseases has been controversial (2-4), and it has not been widely used in Japan (5-7). For example, only $1.5 \%$ of patients received RAI therapy for papillary thyroid carcinoma (PTC) in our department between 1981 and 1991, even though $35 \%$ of the cohort were deemed to have high-risk PTC (8). As Higashi et al. described, there are several reasons for this, including "radiophobia" among Japanese individuals, surgeons' belief in the effectiveness of less than total thyroidectomy (i.e., subtotal thyroidectomy or lobectomy) which precluded use of RAI, and limited availability of facilities for RAI therapy (7).

\section{Availability of RAI therapy}

In Japan, RAI therapy has not been readily provided in 


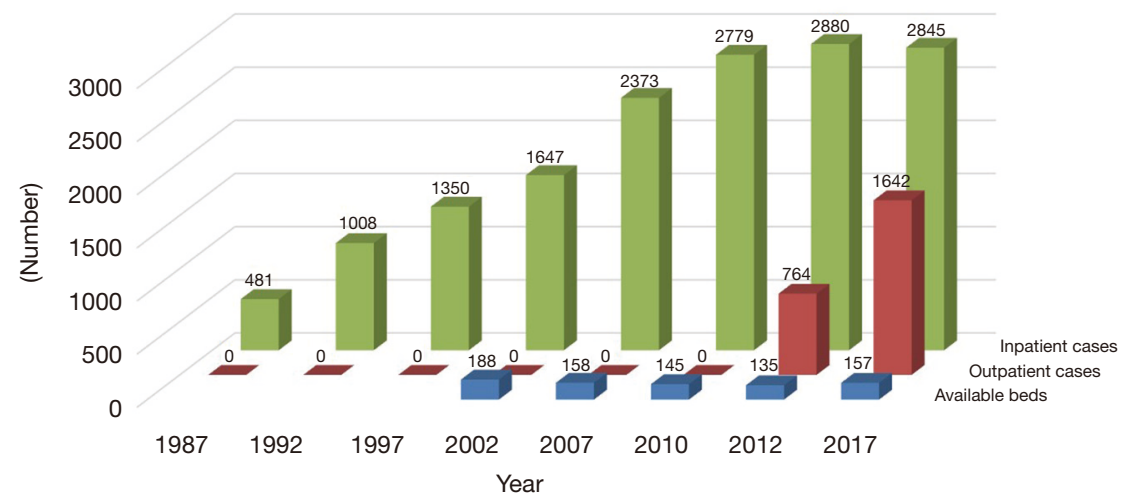

Figure 1 Time trends of the numbers of available beds, outpatient cases, and inpatient cases of RAI therapy for thyroid cancer.

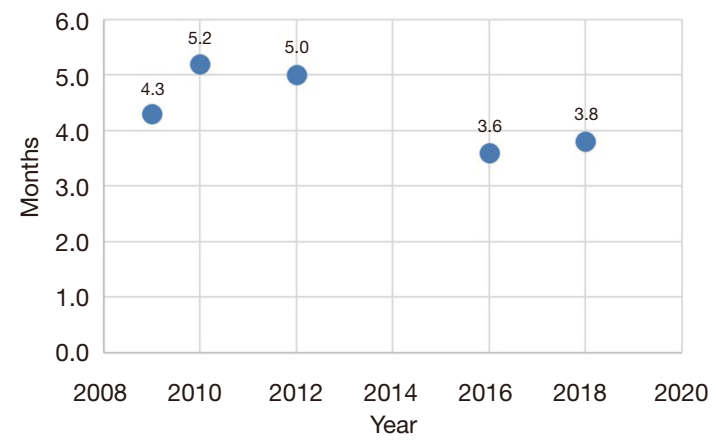

Figure 2 Average waiting time (months) to receive RAI therapy for thyroid cancer.

a timely manner to patients in need $(6,7)$. Successive nationwide surveys on the status quo of RAI therapy for DTC in Japan have revealed that the number of beds dedicated to inpatient care has decreased. In contrast, the number of inpatient cases treated with RAI for adjuvant or therapeutic purposes has increased to nearly 3,000 during the past two decades (Figure 1) (9-14). There are two reasons for the decline in available beds (5-7). First, the Ministry of Health, Labour and Welfare of Japan has established fairly stringent and comprehensive regulations on the use of radioactive materials and release of patients following RAI therapy. Medical institutions have been spending a considerable amount to equip and maintain exclusive facilities, such as shield rooms, local air exhausters, filters, drainage, and waste disposal tanks, to observe the rules. However, the second reason is that the Japanese health insurance system does not fully reimburse the actual expenses. More than $90 \%$ of respondents in the nationwide survey felt that coverage was insufficient (12). Therefore, several hospitals had to abandon RAI therapy because of the financial load (7).

Another problem is that patients with recurrent disease have to wait for a long time to receive RAI therapy. Although the average waiting time decreased from 5.2 months in 2010 to 3.8 months in 2018, there is still room for improvement (Figure 2) (9-13). In fact, the distribution and availability of medical facilities vary across the country, and some patients have to wait for $>9$ months to receive treatment for their metastatic lesions (13). This observation posed serious concerns on the potential effects of such a long waiting period on the oncologic outcomes. Higashi et al. reported that delayed RAI therapy for metastatic DTC was significantly associated with poor disease-specific survival, and the hazard ratio of the interval from surgery to initial RAI therapy $\geq 180$ days compared to that of $<180$ days was 4.22 (95\% CI, 1.55-11.5) (15).

To overcome the potential harm caused by the shortage of dedicated facilities, Japanese experts initiated thyroid remnant ablation for DTC with a dose of $1,110 \mathrm{MBq}$ of RAI in an outpatient clinic, following a pivotal study that examined the safety of the procedure. Kusakabe et al. of the Japanese Society of Nuclear Medicine concluded that outpatient-based ablation with 1,110 MBq of RAI after total thyroidectomy in patients with DTC was safe if applied under appropriate supervision and guidance by experts with specific qualifications (16). The number of patients treated with ablative RAI therapy in an outpatient basis increased from 764 in 2012 to 1,642 in 2017, according to the surveys (Figure 1) (14). In contrast, the number of inpatient cases remained at the same level, and the waiting time did not show a significant change (Figures 1,2). The need for RAI therapy for metastatic lesions can be expected to increase 


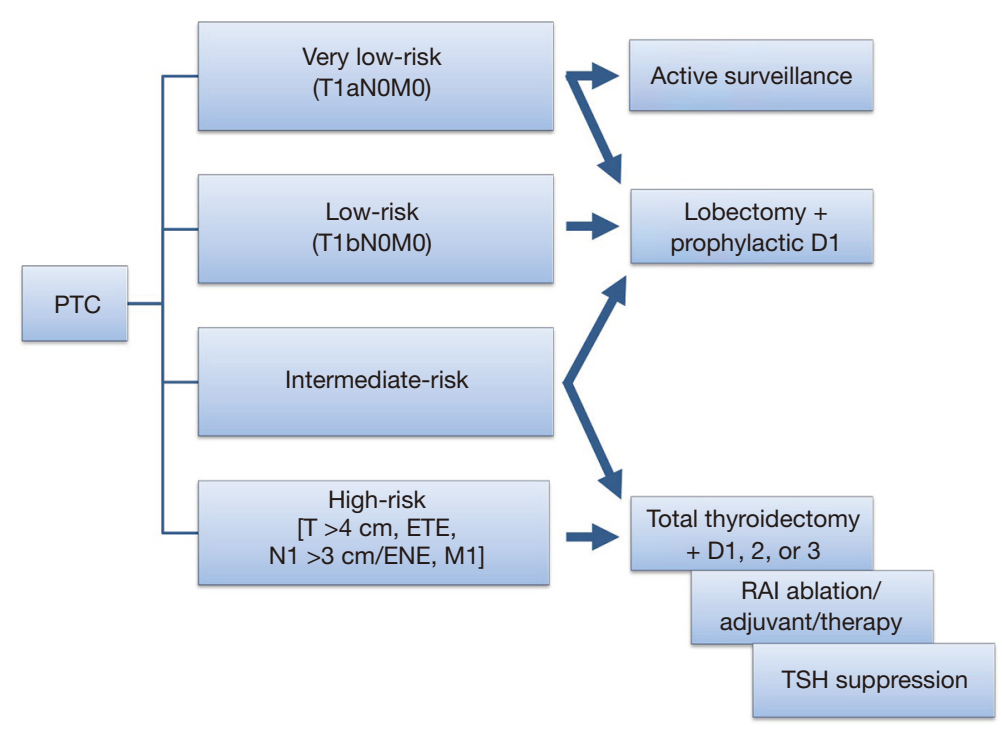

Figure 3 Flowchart of the initial management of PTC (the revised Japanese clinical practice guidelines for thyroid tumors) (20,21). PTC, papillary thyroid carcinoma; ETE, extrathyroidal extension; ENE, extranodal extension; D1, lymph node dissection of the central neck area; D2, lymph node dissection of the unilateral neck area; D3, lymph node dissection of the bilateral neck area.

because patients with PTC with high-risk features have sustained hazard of developing recurrence, even $\geq 10$ years after initial treatment (8). Moreover, it is recommended that RAI therapy be performed first for unresectable progressive DTC, and molecular-targeted drugs are indicated only when the lesions are refractory to the treatment.

\section{Clinical practice guidelines for thyroid cancer}

Following the initial development of the clinical practice guidelines for thyroid tumors in 2010 (17-19), the Japan Association of Endocrine Surgeons (JAES) and the Japanese Society of Thyroid Surgeons (JSTS) revised the guidelines in 2018 (20,21). The guidelines set four risk categories as an initial assessment of PTC based on the pre- or intraoperative findings according to the UICC TNM classification (22): very low-risk PTC measuring $\leq 1 \mathrm{~cm}$ without any metastases (T1aN0M0); low-risk PTC measuring 1.1-2 cm without any metastases (T1bN0M0); high-risk PTC having at least one of the features including tumor size $>4 \mathrm{~cm}$, extrathyroidal extension or extranodal extension to adjacent structures except for the sternothyroid muscle, clinical node metastasis $>3 \mathrm{~cm}$, and M1; and intermediate-risk PTC, which indicates a tumor that does not meet any of the definitions for the very low-, low-, or high-risk categories (17-21). The guidelines are unique in that the management strategies are recommended according to the risk categories (Figure 3). Active surveillance without surgery can be an option for patients with very low-risk PTC, while lobectomy, along with prophylactic central node dissection, is a treatment of choice for very low- and lowrisk PTC. Total thyroidectomy plus appropriate central/ lateral lymph node dissection followed by RAI therapy and thyrotropin suppression therapy is recommended for highrisk PTC. For intermediate-risk PTC, sound judgment is required to determine the extent of thyroidectomy and lymph node dissection by considering each patient's characteristics and prognostic factors.

Considering the poor prognosis associated with highrisk PTC (8), Japanese experts reached a consensus that employing all available treatments would be necessary to reduce oncologic events. This recommendation must have been reflected in the rise of ablative RAI therapy on an outpatient basis during the past decade (Figure 1). However, so far, there is no substantial evidence to support the advantages of total thyroidectomy, ablative RAI therapy, and thyrotropin suppression therapy (21).

\section{RAl therapy: definitions, goals, and evidence}

The Japanese guidelines classify RAI therapy into three categories in line with those set by the latest guidelines developed by the American Thyroid Association (ATA) in 2015: ablation, adjuvant therapy, and treatment (Figure 4) (23). 


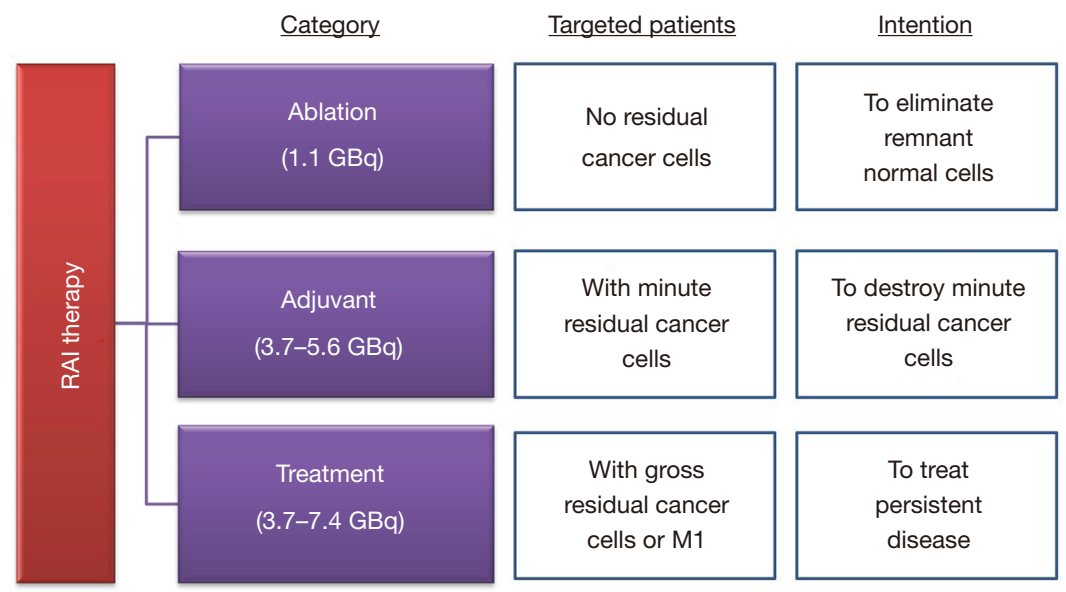

Figure 4 Category, targeted patients, and intention of RAI therapy (the revised Japanese clinical practice guidelines for thyroid tumors) (20,21).

Ablation aims to eliminate remnant normal follicular cells to facilitate the detection of recurrence by measuring thyroglobulin $(\mathrm{Tg})$ levels. Adjuvant therapy is expected to improve recurrence-free and disease-specific survival by destroying microscopic residual cancer cells. RAI treatment is a therapy for a persistent disease that is not suitable for surgical therapy. Although the recommended dose of RAI for adjuvant therapy is $3,700-5,600 \mathrm{MBq}(100-150 \mathrm{mCi})$, it is not attainable in Japan because the dedicated resources have been quite limited, as described above. Some patients who are candidates for adjuvant RAI therapy have been treated with $1,110 \mathrm{MBq}(30 \mathrm{mCi})$ of RAI under "ablation."

\section{Ablation}

Recently, researchers from three institutions in Japan reported the efficacy of ablation using RAI $1,110 \mathrm{MBq}$ (Figure 5) (24-26). Ablation success was achieved in 53\% (95\% CI, 38-68\%) at Gunma University, 74\% (95\% CI, 61-83\%) at Kyoto University, and 23\% (95\% CI, 15-33\%) at Tokyo Women's Medical University. Several factors may explain the observed differences. The criteria in assessing a diagnostic whole-body scan (DxWBS) and the definitions of ablation success were different among the three reports. Particularly, Abe et al. used the most stringent definition for ablation success comprising of negative DxWBS and stimulated $\mathrm{Tg}$ level $<2 \mathrm{ng} / \mathrm{mL}$ compared to that used by the other two studies (26). Study populations were also different in terms of the risk class of PTC. The proportion of patients with high-risk PTC was $23 \%$ at Gunma University, $34 \%$ at Kyoto University, and $45 \%$ at Tokyo Women's
Medical University, whereas that of patients with low-risk PTC was $13 \%, 0 \%$, and $0 \%$, respectively. Furthermore, the investigators from Gunma and Kyoto University classified patients according to the ATA 2015 guidelines, while the authors at the Tokyo Women's Medical University referred to the Japanese 2018 guidelines. The two guidelines differ in some respects in defining the risk class for PTC (Figure 6). The Japanese classification is based on the pre- and intraoperative assessment, while the ATA classification uses pathological evaluation. For example, T3a $(>4 \mathrm{~cm})$ PTC without lymph node metastasis would be classified as high-risk based on the Japanese guidelines, but it would be classified as low-risk based on the ATA guidelines. In contrast, T1b PTC with more than five microscopic lymph node metastases would still be classified as low-risk in Japan, but it would be classified as intermediate-risk in the United States. Nonetheless, all three studies observed that the serum $\mathrm{Tg}$ level, either pretreatment or at the time of treatment, is associated with the success or failure of ablation (24-26).

\section{Adjuvant therapy}

Finding relevant studies showing evidence of effectiveness, harms, and patients' views were vital in formulating recommendations for RAI adjuvant therapy during the revision of the Japanese guidelines. However, the development encountered a few difficulties as follows (20,21): first, some studies included both PTC and FTC under the name "differentiated thyroid carcinoma (DTC)" in the study population. Moreover, the definitions of risk 


\begin{tabular}{|c|c|c|c|}
\hline & $\begin{array}{l}\text { Gunma Univ. } \\
\qquad(\mathrm{n}=47)\end{array}$ & $\begin{array}{l}\text { Kyoto Univ. } \\
(n=119)\end{array}$ & $\begin{array}{c}\text { Tokyo Women's Medical Univ. } \\
(n=119)\end{array}$ \\
\hline Female/male & $34 / 13$ & $80 / 39$ & $74 / 45$ \\
\hline Age (range) & Median 55 (25-79) & Median 54 (9-78) & Median 51 (24-76) \\
\hline $\operatorname{TgAb}+v e$ & NA & $14(12 \%)$ & $24(20 \%)$ \\
\hline Histopathology & PTC 47 (100\%) & $\begin{array}{l}\text { PTC } 115(97 \%) \\
\text { Others } 4(3 \%)\end{array}$ & PTC 119 (100\%) \\
\hline PTC risk class & $\begin{array}{l}\text { ATA } 2015 \text { guidelines: } \\
\text { Low-risk } 13(28 \%) \\
\text { Intermediate-risk } 23(49 \%) \\
\text { High-risk } 11(23 \%)\end{array}$ & $\begin{array}{l}\text { ATA } 2015 \text { guidelines: } \\
\text { Low-risk } 0 \text { (0\%) } \\
\text { Intermediate-risk } 79 \text { (66\%) } \\
\text { High-risk } 40(34 \%)\end{array}$ & $\begin{array}{l}\text { JPN } 2018 \text { guidelines: } \\
\text { Low-risk } 0 \text { (0\%) } \\
\text { Intermediate-risk } 65 \text { (55\%) } \\
\text { High-risk } 54(45 \%)\end{array}$ \\
\hline $\begin{array}{l}\text { Time from surgery } \\
\text { to RAI }\end{array}$ & NA & NA & Median 122 days (35-840) \\
\hline Ablation dose & $1,110 \mathrm{MBq} 47$ (100\%) & $\begin{array}{l}1,110 \mathrm{MBq} \quad 68(57 \%) \\
2,960-3,700 \mathrm{MBq} 51(43 \%)\end{array}$ & $1,110 \mathrm{MBq} 119$ (100\%) \\
\hline $\begin{array}{l}\text { Time from ablation } \\
\text { to DxWBS }\end{array}$ & (6 months) & & Median 261 days (148-560) \\
\hline DxWBS dose & 370 MBq 47 (100\%) & $119(100 \%)$ & 370 or $1,110 \mathrm{MBq} 119(100 \%)$ \\
\hline DxWBS assessment & $\begin{array}{l}\text { - No/faint uptake } \\
\text { - Medium uptake } \\
\text { - High uptake }\end{array}$ & $\begin{array}{l}\text { - Negative scan: }<0.1 \% \\
\text { uptake on the basis of the } \\
\text { region-of-interest method }\end{array}$ & $\begin{array}{l}\text { - Negative: negative } \\
\text { equivocal } \\
\text { - Positive: probably } \\
\text { definitively positive }\end{array}$ \\
\hline Ablation success & $\begin{array}{l}\text { - Negative DxWBS and } \\
\text { stimulated (TSH >30) } \\
\mathrm{Tg} \leq 5 \mathrm{ng} / \mathrm{mL} 25(53 \%)\end{array}$ & $\begin{array}{l}\text { Negative DxWBS \& } \\
\text { unstimulated } \mathrm{Tg}<2.0 \mathrm{ng} / \mathrm{mL} \\
\text { - Low dose: } 50(74 \%) \\
\text { - High dose: } 36(71 \%)\end{array}$ & $\begin{array}{l}\text { a. Negative DxWBS } 69(58 \%) \\
\text { b. Stimulated }(\mathrm{TSH}>30) \\
\mathrm{Tg}<2.0 \mathrm{ng} / \mathrm{mL} 35(37 \%)^{*} \\
\text { c. } \mathrm{a}+\mathrm{b} 22(23 \%)^{*}\end{array}$ \\
\hline
\end{tabular}

Figure 5 Efficacy of ablation using 1,110 MBq in Japan. TgAb, anti-thyroglobulin antibody; PTC, papillary thyroid carcinoma; ATA, American Thyroid Association; JPN, Japanese; NA, not available; DxWBS, diagnostic whole-body scan; Tg, thyroglobulin.

\begin{tabular}{|l|c|c|c|}
\multicolumn{1}{|c|}{} & \multicolumn{2}{|c|}{ Risk classification of PTC $(\mathrm{M} 0)$} \\
\hline JPN 2018 Gls & cN0 & $\begin{array}{c}\text { cN1 }(\leq 3 \mathrm{~cm}) \text { \& no } \\
\text { ENE }\end{array}$ & cN1 $(>3 \mathrm{~cm})$ \& ENE \\
\hline T1a $(\leq 1 \mathrm{~cm})$ & Very low & Intermediate & High \\
\hline T1b $(1 \sim 2 \mathrm{~cm})$ & Low & Intermediate & High \\
\hline T2 $(2<\sim 4 \mathrm{~cm})$ & Intermediate & Intermediate & High \\
\hline T3a $(>4 \mathrm{~cm})$ & High & High & High \\
\hline $\mathrm{T} 4(\mathrm{ETE})$ & High & High & High \\
\hline \hline
\end{tabular}

\begin{tabular}{|l|c|c|c|c|}
\hline \multicolumn{1}{|c|}{ ATA $2015 \mathrm{GLs}$} & $\mathrm{pNO}$ & $\mathrm{pN1}(\leq 5 \mathrm{mets})$ & $\mathrm{pN1}(>5$ mets $)$ & $\mathrm{pN1}(>3 \mathrm{~cm})$ \\
\cline { 2 - 4 } No ETE & Low & Low & Intermediate* & High \\
\hline Microscopic ETE & Intermediate & Intermediate & Intermediate* & High \\
\hline Macroscopic ETE & High & High & High & High \\
\hline $\begin{array}{l}\text { Incomplete } \\
\text { tumor resection }\end{array}$ & High & High & High & High \\
\hline
\end{tabular}

*intermediate-risk: also aggressive histology (tall cell, hobnail, columnar cell) or vascular invasion ETE: extra-thyroidal extension

Figure 6 Risk classification of PTC. PTC, papillary thyroid carcinoma; ETE, extrathyroidal extension; ENE, extranodal extension. 


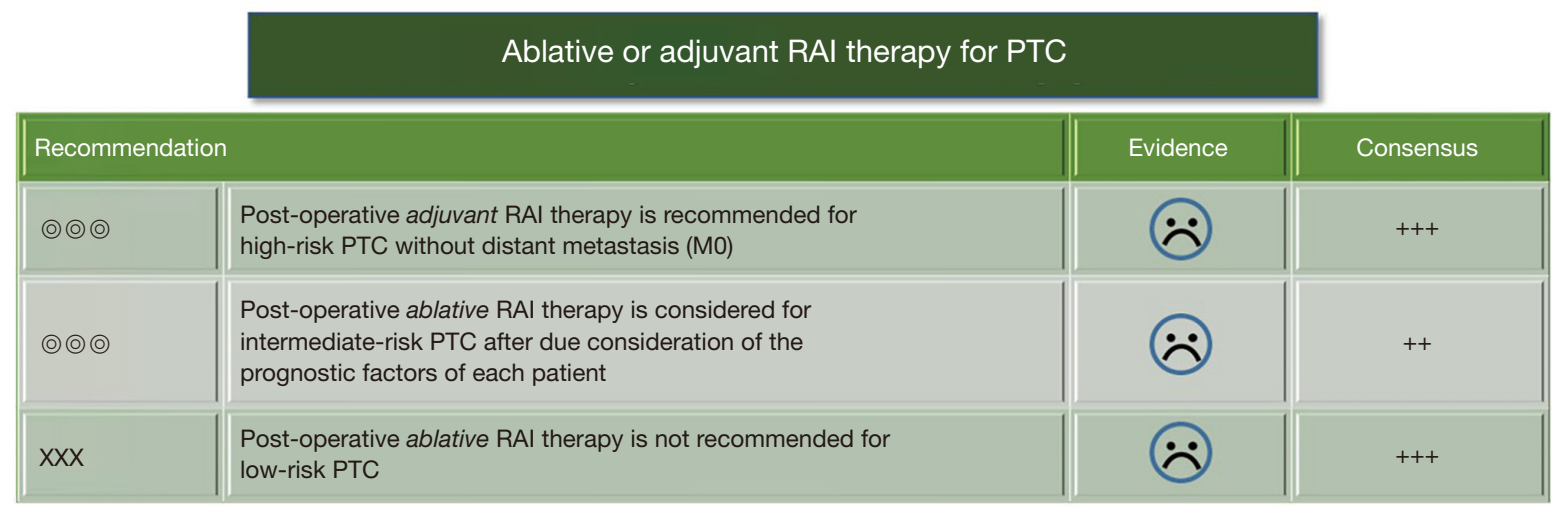

\begin{tabular}{|c|c|}
\hline Outcome & Evidence \\
\hline Effectiveness & $\begin{array}{l}\text { - High-risk PTC: Use of RAI for Stage III or IV patients with DTC was associated with risk ratios of } 0.74 \\
\text { for all-cause mortality, } 0.68 \text { for cancer death, and } 0.76 \text { for cancer recurrence. } \\
\text { - Intermediate-risk PTC: RAI administration was associated with a better overall survival with } \\
\text { hazard ratio of } 0.71 \text { for the entire population and } 0.64 \text { for patients }<45 \text { years-old, respectively, with } \\
\text { T3NOM0-x or T1-3N1M0-x PTC. } \\
\text { - Low-risk PTC: RAI therapy has not been demonstrated to be effective in suppressing low risks of } \\
\text { recurrence or death. }\end{array}$ \\
\hline Harms & $\begin{array}{l}\text { - Acute side effects, gastrointestinal symptoms, and radiation sialadenitis occurred in } 60-70 \% \text { of } \\
\text { patients. Temporary effects on gonadal function and bone marrow may occur. Therapy-induced } \\
\text { carcinoma may occur with an increase in dose, but the incidence is very low. }\end{array}$ \\
\hline $\begin{array}{l}\text { Health conditions from } \\
\text { patients' perspective }\end{array}$ & $\begin{array}{l}\text { - Patients reported that "diagnosis of thyroid carcinoma is a life-changing event," "it is not easy to } \\
\text { determine to undergo RAl therapy," and "experienced various symptoms after RAl therapy." }\end{array}$ \\
\hline
\end{tabular}

Figure 7 Ablative or adjuvant RAI therapy for PTC (the revised Japanese clinical practice guidelines for thyroid tumors) (20,21). PTC, papillary thyroid carcinoma.

class varied among studies and were different from those in the revised Japanese guidelines. Second, the distinction between "ablation", "adjuvant", and "treatment" was not always made accordingly, even in the relevant literature. Finally, there was a wide variation in the RAI doses among the studies.

Figure 7 summarizes the recommendations and evidence of ablative or adjuvant therapy for PTC presented in the Japanese 2018 guidelines $(20,21)$. The optimal extent of thyroidectomy for low-risk PTC is lobectomy. Thus, RAI ablation is not recommended. There were no reports in which the study population fit the classification of intermediate-risk PTC defined by the Japanese 2018 guidelines. Ruel et al. demonstrated the association between RAI administration and all-cause mortality in 21,870 cases of intermediate-risk PTC (pT3N0cM0-x, pT1-3N1cM0-x) registered in the National Cancer Database in the United
States (27). The hazard ratio of adding RAI therapy was 0.71 (95\% CI, 0.62-0.82) for the entire population and 0.64 (95\% CI, 0.45-0.92) for patients aged $<45$ years. However, the absolute risk differences were quite small $[1.9 \%(95 \%$ CI, $1.2-2.6 \%)$ for the entire population and $0.6 \%(95 \%$ CI, $0.1-1.1 \%)]$ for patients aged $<45$ years). Jonklaas et al. defined Stages III or IV DTC as high-risk disease and reported that adjuvant RAI therapy was associated with improved survival. The estimated risk ratios were 0.74 (95\% CI, 0.63-0.91) for all-cause mortality, 0.68 (95\% CI, $0.53-0.88)$ for carcinoma death, and 0.76 (95\% CI, 0.600.68 ) for carcinoma recurrence (28). The literature does not demonstrate that the use of adjuvant RAI therapy is effective in preventing oncologic outcomes in patients with high-risk PTC defined by the Japanese 2018 guidelines. Therefore, the quality of evidence supporting each recommendation was marked with representing poor evidence $(20,21)$. 


\begin{tabular}{|c|c|c|c|c|}
\hline \multicolumn{3}{|c|}{ Recommendation } & Evidence & Consensus \\
\hline ○๑) & \multicolumn{2}{|c|}{ RAI therapy is strongly recommended for lung metastasis. } & & +++ \\
\hline (๑) ๑ & \multicolumn{2}{|c|}{ RAI therapy is strongly recommended for bone metastasis. } & & ++ \\
\hline () & \multicolumn{2}{|c|}{$\begin{array}{l}\text { RAl therapy is weakly recommended for either local recurrence or lymph } \\
\text { node metastasis that is inoperable but requires therapy. }\end{array}$} & & ++ \\
\hline$x X X$ & \multicolumn{2}{|c|}{ RAI therapy is not recommended for brain metastasis. } & & +++ \\
\hline \multicolumn{2}{|l|}{ Outcome } & \multicolumn{3}{|l|}{ Evidence } \\
\hline \multicolumn{2}{|l|}{ Effectiveness } & \multicolumn{3}{|c|}{$\begin{array}{l}\text { - The response rate for lung metastasis showing iodine accumulation has been estimated to be } 17 \% \\
\text { for complete response (CR), } 44 \% \text { for partial response (PR), } 33 \% \text { for stable disease (SD), and } 6 \% \text { for } \\
\text { progressive disease (PD). } \\
\text { - } 5 \text {-year, } 10 \text {-year, and } 15 \text {-year survival rates of cases with lung metastasis showing iodine accumulation } \\
\text { have been estimated at } 87 \%, 69 \% \text {, and } 56 \% \text {, respectively. } \\
\text { - } 5 \text {-year, } 10 \text {-year, and } 15 \text {-year survival rates of cases with lung metastasis without iodine accumulation } \\
\text { have been estimated at } 70 \%, 38 \% \text {, and } 21 \% \text {, respectively. } \\
\text { - The rate of CR for bone metastasis was } 50 \% \text { in } 8 \text { cases aged } 45 \text { years or younger, and } 21 \% \text { for } 99 \\
\text { cases older than } 45 \text { years. }\end{array}$} \\
\hline \multicolumn{2}{|l|}{ Harms } & \multicolumn{3}{|l|}{ - The incidence of blood system disorders was reported as $37 \%$. } \\
\hline \multicolumn{2}{|c|}{$\begin{array}{l}\text { Health conditions from } \\
\text { patients' perspective }\end{array}$} & \multicolumn{3}{|l|}{ - No reports have inquired about the patients' perspective. } \\
\hline
\end{tabular}

Figure 8 RAI treatment for recurrent PTC (the revised Japanese clinical practice guidelines for thyroid tumors) (20,21). PTC, papillary thyroid carcinoma.

\section{Treatment}

RAI therapy is strongly recommended for lung or bone metastasis, while it is weakly recommended either local recurrence or lymph node metastasis that is inoperable for some reason but requires therapy. Although the Japanese 2018 guidelines cited some numerical data from the literature regarding the effectiveness of the treatment (Figure 8), the validity of such estimates is unsatisfactory because of the retrospective nature of their designs, limited number of subjects, and concomitant interventions that made patients' clinical courses complex $(20,21)$.

\section{Dynamic evaluations and decisions}

The definitions of RAI ablative or adjuvant therapy are apparent. However, clinical judgments may change according to the findings of imaging studies and serum $\mathrm{Tg}$ levels (Figure 9). When a patient is found to have residual accumulations outside the thyroid beds on the wholebody scan following RAI administration and the lesions are confirmed by other imaging modalities, the individual must have treatments with either RAI $\geq 3,700 \mathrm{MBq}$ or salvage surgery. In contrast, if the scan shows I-131 accumulation in the thyroid bed alone, then a decision will be made based on a follow-up diagnostic scan (DxWBS) and serum $\mathrm{Tg}$ level at 6-12 months. A patient has no residual disease when the DxWBS shows no accumulation of RAI and stimulated Tg level $<2 \mathrm{ng} / \mathrm{mL}$. In patients with uncertain responses defined by either a positive DxWBS scan at the thyroid bed or stimulated $\mathrm{Tg}$ level $\geq 2 \mathrm{ng} / \mathrm{mL}$, a second administration of $\mathrm{RAI} \geq 1,110 \mathrm{MBq}$ needs to be considered.

\section{Future directions}

While RAI treatment is a crucial element in the management of differentiated thyroid carcinoma throughout 


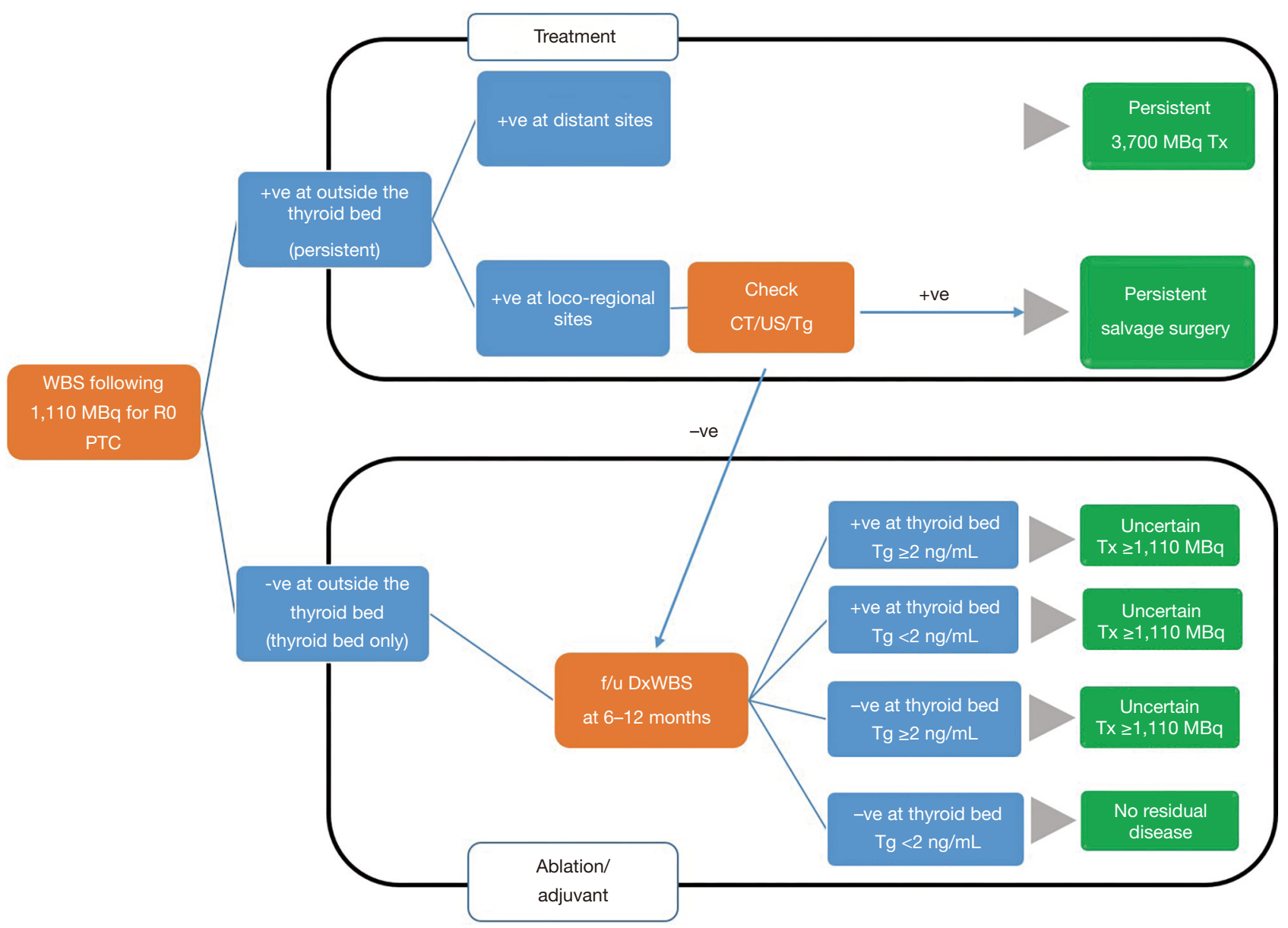

Figure 9 Dynamic evaluations and decisions on ablative or adjuvant RAI therapy. WBS, whole-body scan; R0, curative resection; +ve, positive; -ve, negative; DxWBS, diagnostic whole-body scan; CT, computed tomography; US, ultrasonography; Tg, serum thyroglobulin level.

the world, its use in Japan has been unique as compared to that in other countries due to various reasons. Now thanks to an evidence-based approach, we recognize no apparent differences in the recommendations for RAI use between in our latest guidelines and those in western ones (23).

The objective of the JAES 2018 guidelines is to improve health-related outcomes in patients with thyroid tumors by minimizing gaps in knowledge among physicians. However, further clinical research is needed to make shared decision more evidence based. It is vital to conduct studies to examine the long-term outcomes of patients with intermediate- or high-risk PTC in Japan, yet such reports have never been published. The ablation success rate can be an alternative measure to determine the efficacy of RAI therapy using 1,110 MBq. Abe et al. concluded that low-dose RAI therapy might be inadequate in achieving successful ablation based on their observations (26). To this end, we are still facing the barrier to provide RAI therapy to patients as appropriate. Japanese experts in nuclear medicine have been making efforts to obtain approval for high-dose RAI administration on an outpatient basis to overcome the limited availability of resources for therapy (29). All relevant health professionals need to work closely in practice and research to ameliorate the current situation to care for patients with thyroid cancer.

\section{Acknowledgments}

The authors dedicate this article to Dr. Kiyoko Kusakabe, who cared for patients and taught us humane clinical practice at Tokyo Women's Medical University.

Funding: None. 


\section{Footnote}

Provenance and Peer Review: This article was commissioned by the Guest Editor (Kennichi Kakudo) for the series "Asian and Western Practice in Thyroid Pathology: Similarities and Differences" published in Gland Surgery. The article was sent for external peer review organized by the Guest Editor and the editorial office.

Conflicts of Interest: All authors have completed the ICMJE uniform disclosure form (available at http:// dx.doi.org/10.21037/gs-20-378). The series "Asian and Western Practice in Thyroid Pathology: Similarities and Differences" was commissioned by the editorial office without any funding or sponsorship. TO reports grants (Scholarship donations) from Taiho, Eizai, Chugai, outside the submitted work. The authors have no other conflicts of interest to declare.

Ethical Statement: The authors are accountable for all aspects of the work in ensuring that questions related to the accuracy or integrity of any part of the work are appropriately investigated and resolved.

Open Access Statement: This is an Open Access article distributed in accordance with the Creative Commons Attribution-NonCommercial-NoDerivs 4.0 International License (CC BY-NC-ND 4.0), which permits the noncommercial replication and distribution of the article with the strict proviso that no changes or edits are made and the original work is properly cited (including links to both the formal publication through the relevant DOI and the license). See: https://creativecommons.org/licenses/by-nc-nd/4.0/.

\section{References}

1. Durante C, Haddy N, Baudin E, et al. Long-term outcome of 444 patients with distant metastases from papillary and follicular thyroid carcinoma: benefits and limits of radioiodine therapy. J Clin Endocrinol Metab 2006;91:2892-9.

2. Sawka AM, Brierley JD, Tsang RW, et al. An updated systematic review and commentary examining the effectiveness of radioactive iodine remnant ablation in well-differentiated thyroid cancer. Endocrinol Metab Clin North Am 2008;37:457-80.

3. Lamartina L, Durante C, Filetti S, et al. Low-risk differentiated thyroid cancer and radioiodine remnant ablation: a systematic review of the literature. J Clin Endocrinol Metab 2015;100:1748-61.

4. Verburg FA, Flux G, Giovanella L, et al. Differentiated thyroid cancer patients potentially benefitting from postoperative I-131 therapy: a review of the literature of the past decade. Eur J Nucl Med Mol Imaging 2020;47:78-83.

5. Shigematsu N, Takami H, Ito N, et al. Unique treatment policy for well-differentiated thyroid cancer in Japan: results of a questionnaire distributed to members of the Japanese Society of Thyroid Surgery and the International Association of Endocrine Surgeons. Endocr J 2006;53:829-39.

6. Okamoto T. Radioactive iodine treatment for differentiated thyroid carcinoma in Japan. Surgery 2010;147:432-3.

7. Higashi T, Kudo T, Kinuya S. Radioactive iodine (131I) therapy for differentiated thyroid cancer in Japan: current issues with historical review and future perspective. Ann Nucl Med 2012;26:99-112.

8. Dong W, Horiuchi K, Tokumitsu H, et al. Time-varying pattern of mortality and recurrence from papillary thyroid cancer: lessons from a long-term follow-up. Thyroid 2019;29:802-8.

9. Kusakabe K, Okamoto T, Nakano K, et al. A surveillance report on the actual operational status of the medical ward environment for radioactive iodine therapy of differentiated thyroid cancers in Japan (the first survey in 2009). Isotope News 2010;672:25-9.

10. Koizumi K, Kusakabe K, Okamoto T, et al. The second surveillance report on the actual operational status of the medical ward environment for radioactive iodine therapy of differentiated thyroid cancers in Japan (the 2nd survey in 2010). Kaku Igaku 2011;48:15-7.

11. Koizumi K, Okamoto T, Abe K, et al. The third surveillance report on the actual operational status of the medical ward environment for radioactive iodine therapy of differentiated thyroid cancers in Japan (the 3rd survey in 2012). Kaku Igaku 2014;51:387-96.

12. Koizumi K, Abe K, Okamoto T, et al. The fourth surveillance report on the actual operational status of the medical ward environment for radioactive iodine therapy of differentiated thyroid cancers in Japan (the 4th survey in 2016). Kaku Igaku 2017;54:579-86.

13. Abe K, Okamoto T, Kanaya K, et al. The fifth surveillance report on the actual operational status of the medical ward environment for radioactive iodine therapy of differentiated thyroid cancers in Japan (the 5th survey in 2018). Kaku Igaku 2019;56:107-16. 
14. Nishiyama Y, Kinuya S, Kato T, et al. Nuclear medicine practice in Japan: a report of the eighth nationwide survey in 2017. Ann Nucl Med 2019;33:725-32.

15. Higashi T, Nishii R, Yamada S, et al. Delayed initial radioactive iodine therapy resulted in poor survival in patients with metastatic differentiated thyroid carcinoma: a retrospective statistical analysis of 198 cases. J Nucl Med 2011;52:683-9.

16. Kusakabe K, Yokoyama K, Ito K, et al. Thyroid remnant ablation using $1,110 \mathrm{MBq}$ of I-131 after total thyroidectomy: regulatory considerations on release of patients after unsealed radioiodine therapy. Ann Nucl Med 2012;26:370-8.

17. The Japanese Society of Thyroid Surgery/The Japan Society of Endocrine Surgeons. Guidelines for the management of thyroid tumors. Tokyo: Kanehara \& Co., Ltd, 2010.

18. Takami H, Ito Y, Okamoto T, et al. Therapeutic strategy for differentiated thyroid carcinoma in Japan based on a newly established guideline managed by Japanese Society of Thyroid Surgeons and Japanese Association of Endocrine Surgeons. World J Surg 2011;35:111-21.

19. Takami, H, Ito Y, Noguchi H, Yoshida A, et al. (eds). Treatment of thyroid tumor: Japanese clinical guidelines. Tokyo: Springer, 2013.

20. The JAES/JSTS Task Force on the Guidelines for Thyroid Tumors. Clinical practice guidelines on the management of thyroid tumors 2018. J JAES JSTS2018;35:1-87.

21. Ito $\mathrm{Y}$, Onoda $\mathrm{N}$, Okamoto $\mathrm{T}$, et al. The revised clinical practice guidelines on the management of thyroid tumors by the Japan Associations of Endocrine Surgeons: core questions and recommendations for treatments of thyroid

Cite this article as: Okamoto T, Omi Y, Yoshida Y, Horiuchi K, Abe K. Radioactive iodine treatment of papillary thyroid carcinoma in Japan. Gland Surg 2020;9(5):1698-1707. doi: $10.21037 /$ gs-20-378 cancer. Endocr J 2020. [Epub ahead of print].

22. Sobin LH, Gospodarowicz MK, Wittekind Ch (eds). TNM classification of malignant tumours. 7 th edition. John Wiley \& Sons, Inc., 2010.

23. Haugen BR, Alexander EK, Bible KC, et al. 2015 American Thyroid Association management guidelines for adult patients with thyroid nodules and differentiated thyroid cancer: The American Thyroid Association (ATA) Guidelines Taskforce on Thyroid Nodules and Differentiated Thyroid Cancer. Thyroid 2016;26:1-133.

24. Higuchi T, Achmad A, Binh DD, et al. Determining patient selection tool and response predictor for outpatient $30 \mathrm{mCi}$ radioiodine ablation dose in non-metastatic differentiated thyroid carcinoma: a Japanese perspective. Endocr J 2018;65:345-57.

25. Iizuka Y, Katagiri T, Ogura K, et al. Comparison between the different doses of radioactive iodine ablation prescribed in patients with intermediate-to-high-risk differentiated thyroid cancer. Ann Nucl Med 2019;33:495-501.

26. Abe K, Ishizaki U, Ono T, et al. Low-dose radioiodine therapy for patients with intermediate- to highrisk differentiated thyroid cancer. Ann Nucl Med 2020;34:144-51.

27. Ruel E, Thomas S, Dinan M, et al. Adjuvant radioactive iodine therapy is associated with improved survival for patients with intermediate-risk papillary thyroid cancer. J Clin Endocrinol Metab 2015;100:1529-36.

28. Jonklaas J, Sarlis NJ, Litofsky D, et al. Outcomes of patients with differentiated thyroid carcinoma following initial therapy. Thyroid 2006;16:1229-42.

29. Kinuya S. Current status of radioiodine therapy in the world and perspective in Japan. J JAES JSTS 2018;35:192-5. 